bility for planning and administration also needs to be decentralized as well. This is especially true for the large cities, which are probably the best provided with stationary services for handicapped children, in the form of medical schools, larger hospitals, rehabilitation services, special schools or classes, vocational agencies, etc. Furthermore, consideration should be given to locating satellite services for handicapped children in the low-income areas of the large cities.

\title{
Homosexuality-Its Origins, Early Recognition and Prevention
}

\author{
Charles W. Davenport, M.D.*
}

$\mathrm{H}$ adult sexual deviation. The diagnosis of "homosexual personality disorder" is made in the adult who prefers a member of the same sex as a partner for the achievement of sexual gratification. Most professionals look upon homosexuality as an illness, but in actual practice their diagnosis and management of this condition becomes confused because of their emotional reactions to these patients.

The Gay Liberation Movement is making it abundantly clear that homosexuality is not as uncommon as many clinicians used to think. Indeed, Kinsey ${ }^{8}$ reported that between adolescence and old age about 37 per cent of all American men do experience some overt homosexual experience to the point of orgasm, and that four per cent of all white men remain exclusively homosexual all of their lives. In women the rate of homosexuality is one-half the rate of men. The denial of the problem by physicians is an example of the way in which emotional reactions to this disorder prevent early recognition and treatment.

While there is wide disagreement in the literature as to whether homosexuality should be considered a disorder or a way of life, most experts on human sexuality agree that homosexuality is a consequence of disturbed development. The choice of sexual objects (heterosexual or homosexual) is not based upon instinct but is learned behavior derived from the culture and environment of each individual. According to most au-

* Instructor in Psychiatry at the University of Michigan Medical School, Children's Psychiatric Hospital, Ann Arbor, Mich. 48104. thorities, ${ }^{4,7,10-12}$ genetic, constitutional and glandular factors have little importance in the causation of homosexuality, whereas psychologic, social and cultural factors do play key roles. Indeed, recent studies 10,12 suggest that gender identification as a male or female becomes established during the first three to six months of life and can be independent of genetic, morphologic or early hormonal influences.

In other words, gender identity depends overwhelmingly upon the child's sex of rearing rather than upon biological sex. Thus, deviation from normal heterosexual orientation begins early in childhood.

It will be my thesis that pediatricians are in a unique position to recognize predisposing factors early in life, and that they can use their influence to correct environmental factors which are instrumental in the development of adult homosexual. ity. Even though gender identity is fixed at such an early age, psychosexual development does continue throughout childhood and adolescence. Consequently the diagnosis of homosexuality is not appropriate until late adolescence. The potential for such an outcome, however, can be predicted earlier in childhood.

\section{Normal Development}

Although preschool children have often been looked upon as nonsexual, they have specific sexual pleasures of their own. Male erections and self-stimulation go on from early in childhood. Even infants experience inadvertent stimulation in the course of bathing and diapering. The infant recognizes attachment to both parents on 
the basis of their function rather than their membership in one or the other sex. Gradually between the ages of two and one-half years and five years, the child becomes aware of sexual differences and of ways of consciously stimulating himself. Children at this age are stimulated by fantasies, as well as through exploration and sex play with peers.

Parents are often concerned when their child focuses attention upon his genitals as a source of interest, curiosity and pleasure. Their anxiety, shame or even guilt may then be translated into suppressing the child's sexual curiosity and exploration. This reaction results in conflicts and inhibitions which, though they become unconscious, will be influential in setting a pattern of reaction to sexual drives in later life.

Positive attachment to the parent of the opposite sex must be expected and corresponds to future adult heterosexuality. The parents' comfort and acceptance of their own sexual identity and behavior determine the child's perception of the advantages of his own sexual identity. Indeed, identification with the parent of the same sex is a major task of the child during the oedipal years.

Early in childhood, the child is well aware that he is physically, emotionally and intellectually unprepared to enter into the adult world. During this latency period, his sexual impulses and conflicts are relatively reduced. Unless stimulated, his sexual interests are not much evident in daily behavior. He identifies consciously with parents, teachers and others, all of whom help to determine what his appropriate sex behavior should be. He rather clearly tries to incorporate the family morals. He is quite sensitive to the conscious and unconscious attitudes of the family about sexuality. Thus, he may learn that his sexuality is normal and healthy, or that there is something apparently wrong and bad about it. He will mimic the family patterns of modesty or immodesty. A child of latency age typically prefers peers of his own sex. This is based on identification with the partner and not on love.

The boy who is headed for later homosexuality prefers to play with girls and to avoid the rough, competitive masculine activities. The tomboy girl is a less reliable predictor. She is apt to be accepted socially, and often does not make a switch to more feminine activity until late latency or early puberty, but then does so successfully. Some children show atypical interest in sexuality during this age. This may represent a developmental arrest or stimulation by the environment, or reaction to stressful situations.

The impact of puberty is dramatic. The sig. nificant biological changes demonstrate physical and sexual maturity to the adolescent. Accompanying the secondary sexual changes and onset of menstruation are sexual sensations. A boy's feelings may place him in conflict with some of the attitudes which he had identified with earlier in life, and he may respond with strict inhibitions, or by acting out sexual impulses. His behavior may be homosexual, heterosexual or masturbatory. Quite commonly these trends of behavior are not prognostic of future homosexual identification. The culture promotes social contacts with the opposite sex during this period of time, but leaves undefined any expressions of sexuality. The adolescent is thus left with a mixture of curiosity and discomfort in relation to his sexual identity and feelings. The comment of a 13-year-old youngster referred for consultation by distraught parents because "he was caught masturbating with another boy," illustrates this dilemma. The adolescent boy said, "It's rather confusing, because they wouldn't like it if I was doing it with a girl, either."

\section{Factors Promoting Homosexual Development}

I prefer to think of developmental influences which may promote or prevent homosexual development, rather than in terms of prestages of adult homosexuality. In the child's early life, final sexual identity has not yet been developed. The chief causes of abnormal sexual adjustments, including homosexuality, are abnormal parental attitudes and behavior.

The father who is extremely harsh and suppressive when his son shows signs of masculinity can arouse fears which will prevent normal sexual adjustment. The father who is an unsuitable model for masculinity may give rise to a more frank sexual misidentification in his sons. The father who is absent does not provide an identity figure for his sons. The absence may be actual, as in death or divorce, or more subtle (and perhaps more usual) an emotional "absence," or distance.

Bieber, ${ }^{2}$ in the investigation of 106 homosexuals who had undergone analytic treatment, found a family constellation of maternal overprotection with restriction of heterosexual strivings, and paternal detachment with a father who was either hostile or indifferent to his son. Such a father, who is emotionally and physically unavailable, deprives a boy of meaningful masculine contact. In a family like this, the father is submissive and often labeled as a bad father. The situation then becomes more complicated when the mother seeks out the son as a substitute to depend on. Maternal overprotection seems to prevent such a boy from attaining normal peer identification. The mother is often overconcerned about his health and causes him to appear frail and to fear bodily injury. Thus he is discouraged from masculine activities and praised for feminine traits. Although nothers have been frequently discussed in the development of homosexuality, Bieber points to the key role which fathers appear to play. Indeed, he found "a constructive, supportive, warmly related 
father precludes the possibility of a homosexual son." He has apparently never found a homosexual male who has had that quality of relationship with his father.

The factors which promote female homosexual development have been much less studied and are less well defined. The mother who is an unsuitable model for femininity may cause misidentification in her daughters. The girl who is rejected in favor of other siblings by her mother may harbor a repressed longing for the mother, which results in a dependent homosexual attachment in adulthood. Withdrawal of fathers from their developing pubertal daughters can also be traumatic, causing the daughters to beome resentful. In such cases, a girl may either act out heterosexually as an adolescent, or identify herself with the shared interest of the lost love object and thus change to homosexual behavior. Deutch ${ }^{3}$ also reported that fear of father may result in the defense of a girl's identification with the aggressive father. When this happens, the girl becomes as strong as the father and may not fear him. Identification through fear thus becomes another motive for adult homosexuality.

There are studies which indicate that fathers of homosexual girls are typically ones who discourage the development of feminine traits and interests. They are possessive of their daughters and disapprove of boyfriends. This type of father also allies the daughter with himself against the mother, and binds her too closely to him psycho. logically. As with the male homosexual in rela. tion to the father, one finds the mother of such a girl to be remote and unable to protect her daughters or to provide a good model for feminine identification.

We should not forget that some children are born of the opposite sex than their parents had wished for. Consciously or unconsciously, such children are often encouraged in social skill pursuits which would more commonly fall into the domain of the other sex. They may even be given names which clearly belong to the opposite sex.

\section{Early Signs and Recognition}

As with every other disorder, the keystone to considering the possibility of the development of abnormal sexual behavior is to be aware that it may be present, and to look for it. A child's fam. ily may be reluctant to bring their concerns to the physician, which means that he has to be especially perceptive to early signs and symptoms. The family may prefer to ignore early signs, or to be blind to their significance, and hope that the patient will "grow out of it." The pediatrician's own awareness of the precursors of adult homosexuality must enhance his ability to suspect and help prevent the development of such a deviation. During his clinical observations of the parent-child interactions, and their accounts of behavior and interests, he should realize that guidance from him at this early stage may help to avert a later homosexual personality. With care this can be done tactfully, and not arouse concern in the parents.

These children commonly appear to be frail or clumsy. It often develops that they have tremendous fears of injury and illness. Indeed, when truly sick, they have a tendency to slow recovery. School phobia may be an early complaint. The young school phobic demonstrates overdependency on his mother, along with an irrational fear of the school situation.

Such children are usually reluctant to enter into an age-appropriate, aggressive activity. Boys may prefer solitary safe activities at home, or with a peer group of girls. Such early attitudes can become self-perpetuating as the boy fails to develop masculine skills. This, in turn, reinforces his fears of injury or failure in competitive games. Although a certain amount of tomboyish orientation in a girl is acceptable in our culture, it becomes less so as she approaches puberty and adolescence. When it is truly hard to identify a young girl from her male peers, because of dress and attitude, one must consider this as a sign of potential homosexuality.

Children with a tendency toward homosexual development are often pseudomature. This, in essence, exempts them from age-appropriate behavior, and is rationalized in terms of feeling superior. Such an attitude further polarizes their differences from peers and siblings, and helps to account for their description as loners or isolates. At the same time, these youngsters compete vigorously for parental attention and love.

Excessive closeness with the parent of the opposite sex results in stimulation which the child or adolescent is not prepared to defend against. Such stimulation results in a greater degree of sexual exploration, a common comment in the history of homosexuals. These children build up rejection of their own sexuality as a defense against even closer contact with the parent of the opposite sex.

One should also be concerned about a homo. sexual orientation when a youngster is repeatedly approached by older peers and adults with homosexual behavior. There is every evidence that such children who have repeated exposures are consciously or unconsciously making themselves available for being victimized. Further investigation will usually demonstrate other signs and symptoms of poor sexual identification.

\section{Therapeutic Strategies}

As with other emotional problems, homosexual. ity is best managed by prevention. As stated earlier, the pediatrician is in a unique position to recognize early signs of misidentification and offer counsel to the parents of young children in 
the direction of good mental hygiene. It is particularly important that in such consultations both parents should be present, inasmuch as both parents are involved in the dynamics of the family. This also prevents confusion with respect to what the doctor said, and encourages the parents to discuss with each other their attitudes and behavior. Certainly, the preschool child and the latency age child are both very impressionable and sensitive to their parents' reactions. They are in the age range when sex education comes about as much through identification as any other process. Indeed, children will respond to the way the parents tolerate their curiosity and behavior, more than they will to formal instructions about sex. One of the errors commonly made is the attempt by parents to teach young children more than they are capable of learning at that age. Presenting more material than the child can handle at the time can be overstimulating and confusing. Some parents having heard that inhibitions are bad for a child, may thoughtlessly excite their children by purposeful immodesty. Such behavior can be as harmful as extreme prudishness.

The pediatrician should feel responsible to talk with all parents about their own attitudes and responses to their children's growing sexual maturity. He can provide them with the opportunity to discuss their attitudes and behavior, and can give guidance with respect to the effects these are having on their children.

The pediatrician's counsel at potentially traumatic times for young children can be invaluable. He can help parents understand how children's fear of hospitalization and surgical procedures can be transformed into fears of genital injury. He can show them how to be more supportive, and thereby prevent possible emotional trauma for their children. He can be of help during the handling of such things as divorce and death in a family with their potential for catastrophic effects. For example, in the case of a boy who loses his father through death, the physician can help the mother find adult male figures outside the family, in such organizations as Big Brother, Little League or other community organizations.

Consultation with the adolescent directly, as well as with his parents, can help to clarify some of the conflicts which are raised by the onset of puberty as related to previous learning and behavior. Family interviews at such times will help to uncover the dynamics in the family. One may discover that a child has poor self-esteem and that he has difficulty in identifying with the parent of his own sex. Thus, if a boy is found being dominated and emasculated by an aggressive mother, one's success in altering the relationships between both of the parents and the child may make the difference in the final achievement of masculine identification.

Family interviews may clarify some misconceptions, shared by all three, as to what the behavior of a particular adolescent means. In the example cited earlier, the family needed to understand that their son's mutual masturbation was not a cause for alarm and angry rejection, but behavior which falls within the realm of nomality. Such discussions can open up channels for communication in the family which then facilitate normal, healthy development.

There will be times when the pediatrician needs the assistance of a psychiatrist. This should be thought of particularly where a more fixed homosexual orientation seems to be present, as when a child is being repeatedly approached for overt homosexual participation by older peers and adults. The earlier the pathogenic trends in a family can be recognized, however, the less will be the need for such consultation. Furthermore, since many of the pathogenic trends in the family which result in sexual deviations are seen in other psychiatric disorders, although we have focused on the problems of sexual identification, such consultations have a wider preventive scope.

\section{References}

1. Ackerman, N.: The Psychodynamics of Family Life. New York, Basic Books, Inc., 1958.

2. Bieber, 1.: Homosexuality. New York, Basic Books. Inc., 1962.

3. Deutsch, H.: The Psychology of Women, Vol. 1. New York, Grune and Stratton, 1944.

4. Ellis, A.: Constitutional factors in homosexuality: a recxamination of the evidence. In Beigel, $\mathrm{H}$. G., Ed., Advances in Sex Research. New York, Harper and Row, 1963, p. 161.

5. Finch, S.: Introduction to Child Psychiatry. New York, Norton, 1960.

6. Freud, A.: Normality and Pathology in Childhood. International Universities Press, $196 j$.

7. Gergen, J. A.: Physiologic aspects of sexual behavior: genetics, hormones and the central nervous system. In Vincent, C. E., Ed., Human Sexuality in Medical Education and Practice. Springfield, IIl., Charles C Thomas, 1968, p. 184.

8. Kinsey, A. C. et al.: Sexual Behavior in the Human Male. Philadelphia, Saunders, 1948.

9. - et al:: Sexual Behavior in the Human Female. Philadelphia, Saunders, 1953.

10. Money, J.: Factors in the genesis of homosexual ity. In Winokur, G., Ed., Determinants of $\mathrm{Hu}$ man Sexual Behavior. Springfield, Ill., Charles C Thomas, 1963, p. 19.

11. Rubin, I.: Homosexuality. In Vincent, C. E., Ed., Human Sexuality in Medical Education and Practice. Springfield, III, Charles C Thomas, 1968 , p. 496.

12. Stoller, Robert J.: Sex and Gender. London, The Hogarth Press, 1968. 